\title{
What Defines a Good Tumour Antigen?
}

\author{
Emma C. Morris and J. H. F. (Fred) Falkenburg
}

Compared to standard anticancer therapies, such as chemotherapy, small molecule inhibitors and radiation, $\mathrm{T}$ cell immunotherapies have the advantages of a high degree of specificity and durability of response typically associated with cellular therapies. The functional specificity of a $\mathrm{T}$ cell is determined by its antigen recognition receptor and the target antigen (Bjorkman et al. 1987; Garcia et al. 1996).

The majority of CAR-T cells currently applied in clinical practice do not recognize tumour-specific target antigens but pan-B cell antigens (CD19, CD20, CD22) or maturation antigens (e.g., BCMA), which are abundantly expressed cell surface molecules on both malignant and normal cells (Sadelain et al. 2017; June and Sadelain 2018). In reality, these are only 'ideal' or 'good' tumour antigens because the depletion of normal B cells is generally well tolerated. In contrast to endogenous $\mathrm{T}$ cell receptors (TCRs), which are HLA-restricted and recognize peptide-MHC complexes on the target cell surface, CARs recognize extracellular, membranebound targets. These are typically nonpolymorphic proteins or glycoproteins. This is advantageous over TCR-mediated recognition because CAR-T cell therapies are not limited by patient HLA type.

What defines a 'good' tumour antigen for recognition by a CAR-T cell?

1. Extracellular expression (i.e., expressed on the cell surface and readily accessible)

2. Uniform or consistent expression on all malignant cells

3. Not subject to downregulation or deletion (i.e., no escape variants). This only occurs if the antigen is a molecule critical for maintenance of the malignant population

E. C. Morris $(\bowtie)$

Institute of Immunity and Transplantation, University College London, London, UK

e-mail: e.morris@ucl.ac.uk

J. H. F. (Fred) Falkenburg

Leiden University Medical Center, Leiden, The Netherlands

e-mail: j.h.falkenburg@lumc.nl 
4. Should be expressed on malignant stem cells, and

5. Should not be expressed on normal tissue cells, at least not in nonessential normal tissues (i.e., tumour specific).

\section{Tumour-Specific Antigens (TSAs)}

TSAs are highly specific and typically result from genetic mutations within malignant cells that give rise to neoantigens not present in untransformed (nonmalignant) cells (Schumacher and Schreiber 2015; Schumacher et al. 2019). By definition, there is a low likelihood of 'on-target off-tumour' toxicity because the tumour antigen is not expressed on normal cells. 'On-target on-tumour' toxicities and 'offtarget off-tumour' toxicities may occur as a result of CRS or receptor cross-reactivity. Unfortunately, no nonpolymorphic tumour-specific extracellular target antigens are known. The only highly specific extracellular tumour target antigens are neopeptides presented in the context of (polymorphic) HLA molecules.

\section{Multiple Tumour Antigens Resulting in a 'Tumour-Specific Phenotype'}

Recent studies have demonstrated that simultaneous targeting of two or more target antigens may improve tumour specificity and reduce the risk of antigen escape (Shah et al. 2020; Dai et al. 2020). In such cases, one target antigen may be lineagespecific but not tumour specific, but the combination may be tumour specific. For CAR-T cells to be fully activated, the target cell must express both target antigens (i.e., combined antigen expression). This approach is not expected to ameliorate the risk of CRS, and it is difficult to estimate the risk of 'on-target off-tumour' toxicity, which will depend on the ability of CAR-T cells to discriminate between cells with combined or single antigen expression. In this case, there would be a potential risk of 'off-target off-tumour' toxicity for single antigens (expression of a single antigen in normal cells or aberrant antigen expression in normal cells).

\section{Lineage-Specific and Differentiation Antigens}

These antigens are commonly targeted by CAR-T cells and include CD19, CD20, CD22, and BCMA, which are B cell lineage antigens. Lineage-specific antigens can be optimal targets in the case of tumours associated with cell lineages and/or tissues that are nonredundant or temporarily replaceable, such as the B cell lineage, plasma cells, and thyroid, prostate, and ovarian cells. In these circumstances, their function can be rescued by a second therapeutic intervention. For example, profound B cell lymphopenia following CD19 CAR-T cell therapy can result in hypogammaglobulinaemia and absent or impaired vaccine responses, requiring long-term immunoglobulin replacement therapy. More recent developments aimed at generating 
CAR-T cells for treatment of AML and other myeloid malignancies target lineagespecific and differentiation antigens (i.e., CD33 and CD123) but risk profound cytopenia or bone marrow aplasia and depend on the ability to subsequently replace haematopoietic stem cells and myeloid precursors (Gill et al. 2014). Recent preclinical studies have attempted to fine-tune CAR-T cell responses through the incorporation of safety switch mechanisms (Loff et al. 2020). In the case of lineage-specific antigens, 'on-target off-tumour' toxicity is common, resulting in depletion of specific cell lineages or other cells in the case of aberrant antigen expression. CRS may be common, due in part to wide antigen expression in both normal and malignant cells.

\section{Lineage-Specific Polymorphic/Heterogeneic Antigens}

These target antigens are similar to lineage-specific antigens (above) with the advantage that only part of the system is eliminated (following CAR-T cell targeting) due to intrinsic heterogeneity or antigen expression. Examples include targeting immunoglobulin subclasses or kappa versus lambda light chains in association with immunoglobulin receptors.

\section{Key Points}

1. Most CAR-T cells and all currently approved products target lineagespecific antigens.

2. This results in loss of nonmalignant cells that also express these antigens (e.g., normal B cells).

3. With commercially available CAR-T products, these side effects are manageable but may be more limiting with other novel targets under development.

\section{References}

Bjorkman PJ, Saper MA, Samraoui B, et al. Structure of the human class I histocompatibility antigen, HLA-A2. Nature. 1987;329(6139):506-12.

Dai H, Wu Z, Jia H, et al. Bispecific CAR-T cells targeting both CD19 and CD22 for therapy of adults with relapsed or refractory B cell acute lymphoblastic leukemia. J Hematol Oncol. 2020;13(1):30.

Garcia KC, Degano M, Stanfield RL, et al. An alphabeta T cell receptor structure at $2.5 \mathrm{~A}$ and its orientation in the TCR-MHC complex. Science. 1996;274(5285):209-19.

Gill S, Tasian SK, Ruella M, et al. Preclinical targeting of human acute myeloid leukemia and myeloablation using chimeric antigen receptor-modified T cells. Blood. 2014;123:2343-54.

June CH, Sadelain M. Chimeric antigen receptor therapy. N Engl J Med. 2018;379:64-73.

Loff S, Dietrich J, Meyer JE, et al. Rapidly switchable universal CAR-T cells for treatment of CD123-positive leukemia. Mol Ther Oncolytics. 2020;17:408-20.

Sadelain M, Rivière I, Riddell S. Therapeutic T cell engineering. Nature. 2017;545:423-31. 
Schumacher TN, Schreiber RD. Neoantigens in cancer immunotherapy. Science. 2015;348:69-74. Schumacher TN, Scheper W, Kvistborg P. Annu Rev Immunol. 2019;37:172-200.

Shah NN, Johnson BD, Schneider D, et al. Bispecific anti-CD20, anti-CD19 CAR-T cells for relapsed B cell malignancies: a phase 1 dose escalation and expansion trial. Nat Med. 2020;26(10):1569-75.

Open Access This chapter is licensed under the terms of the Creative Commons Attribution 4.0 International License (http://creativecommons.org/licenses/by/4.0/), which permits use, sharing, adaptation, distribution and reproduction in any medium or format, as long as you give appropriate credit to the original author(s) and the source, provide a link to the Creative Commons license and indicate if changes were made.

The images or other third party material in this chapter are included in the chapter's Creative Commons license, unless indicated otherwise in a credit line to the material. If material is not included in the chapter's Creative Commons license and your intended use is not permitted by statutory regulation or exceeds the permitted use, you will need to obtain permission directly from the copyright holder.

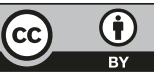

